\title{
ASOCIACIÓN DE FRAGMENTOS DE CERÁMICA DE LOS ESTILOS CAVERNAS Y CHAVINOIDE-ANCÓN DE UN BASURAL DE LAS COLINAS DE ANCÓN
}

\author{
Ernesto E. Tabío
}

Llevando a cabo a fines de setiembre de 1955 una exploración superficial en las colinas de Ancón, el autor acompañado por el Sr. José Casafranca, funcionario de la Dirección de Arqueología e Historia del Perú, hubimos de localizar un sitio en el que aparecían a simple vista gruesas capas de basura arqueológica que contenían una apreciable cantidad de fragmentos de cerámica Chavinoide-Ancón. Este sitio arqueológico, que se encuentra aproximadamente a unos 140 metros al WNW del tanque de agua construido junto al camino a Playa Hermosa, aparecía como expuesto por ciertos trabajos de nivelación llevados a cabo evidentemente para terraplenar una parte de las laderas de las colinas, quizá con el fin de construir algunas casas en ese lugar. El corte efectuado había expuesto capas de antiguos basurales en un espesor visible en algunos lugares de hasta 1.5 metros.

Examinando más detalladamente pudimos constatar que en su parte superior había una estratificación algo mezclada (de unos $0.15 \mathrm{~m}$ ) en que se presentaban algunos pocos fragmentos del estilo Baños de Boza junto con otros, predominantes, del estilo Chavinoide-Ancón (Tabío 1957). En aquella ocasión pudimos recoger in situ algunos ejemplares de fragmentos de los dos estilos mencionados.
Unos días después, el Dr. Jorge C. Muelle, a la sazón Director de Arqueología e Historia, hubo de visitar el sitio en compañía del autor. Como resultado de esta visita hubo de encomendarse el hacer allí, por cuenta del Instituto de Investigaciones Antropológicas, una investigación de tipo estratigráfico.

Por diversos motivos los trabajos no pudieron llevarse a cabo hasta julio de 1956, en cuya oportunidad, con la gentil colaboración de los Sres. Edward Lanning y Frederick Engel, el autor inició la excavación de un pequeño pozo estratigráfico, el que denominaremos para fines de claridad Pozo № 1 y que medía 2.0 × 2.0 $m$ en la superficie.

Tan pronto comenzó el trabajo se decidió excavarlo por niveles naturales. El primer nivel, de unos $0.30 \mathrm{~m}$ en su mayor grosor, dio una buena cantidad de fragmentos del estilo Chavinoide-Ancón, los que estaban mezclados con arena, cenizas y conchas. Excavando el segundo nivel, y como a unos $0.50 \mathrm{~m}$ de la superficie (en la parte de mayor grosor), hubimos de localizar -en basura similar a la descrita en el primer nivel- a un fragmento de cerámica que nos proporcionó una gran sorpresa a todos, pues era evidentemente del estilo Cavernas. Presentaba éste ornamentación incisa y estaba además pintado con pastas resinosas 
aplicadas después de la cocción del ceramio (Tabío 1957).

Esta excavación se continuó hasta una profundidad de unos $0.70 \mathrm{~m}$ (en la parte de mayor grosor), continuando en todo momento la basura dando fragmentos Chavinoide-Ancón.

De nuevo los trabajos se interrumpieron por circunstancias ajenas a nuestra voluntad. Más tarde, a principios de agosto de 1957, se reanudaron las labores, pero esta vez acompañaban al autor, la Srta. Rosa Fung y el Sr. Edward Lanning. Por haber existido cierta infortunada confusión al marcar en el laboratorio los fragmentos colectados en la excavación anterior, se decidió hacer de nuevo un pozo estratigráfico, al que dominamos Pozo № 2. Procedimos a excavarlo dejando el nuevo más al NE. Los niveles 1 y 2 (0.00-0.25 y 0.25 y 0.50 $\mathrm{m})$ arrojaron una gran cantidad de fragmentos Chavinoide-Ancón, en los que predominaban el tipo "Ancón Zoned Punctated" de Willey (Willey 1954).

Casi al comenzar a excavar el nivel 3 (0.5 $0.75 \mathrm{~m}$.) colectamos otro fragmento de cerámica tipo Cavernas. Este era algo más pequeño que el anterior y no presentaba claramente restos de pintura a base de pastas resinosas. Comparando los dos fragmentos de tipo $\mathrm{Pa}$ racas (ambos eran bordes de vasija) pudimos constatar que se trataba de pedazos de dos ceramios distintos.

Sobre la posición absoluta de estos importantes fragmentos conviene aclarar que éstos quedaban en realidad a sólo unos $0.25 \mathrm{~m}$ de profundidad de la superficie actual del basural, ya que el terreno, situado en la falda del cerro, forma un ángulo con la horizontal de unos 20응 aproximadamente.

En este nivel $3(0.5-0.75 \mathrm{~m})$ los fragmentos Chavinoide-Ancón resultaron muy abundantes y además se pudo colectar en él una punta de dardo en piedra negra. En el nivel 4 (0.75$1.0 \mathrm{~m}$ ) seguían apareciendo los fragmentos Chavinoide-Ancón en gran número, también en este recogimos otra punta de dardo en piedra de color gris.
Pocos días después continuamos la excavación, completando los niveles 5 y 6 (1.0-1.25 y $1.25-1.5 \mathrm{~m}$ respectivamente). Ambos dieron gran cantidad de fragmentos del tipo Chavinoide-Ancón, muy especialmente el nivel 5. Cuando llegamos al fondo del nivel 6 el basural parecía continuar en toda su potencia. A esa profundidad interrumpimos temporalmente esta excavación tan interesante.

\section{Bibliografía}

ANÓNIMO

1953 "Mesa Redonda para Regular la Terminología Arqueológica Peruana". Bol. Soc. para Antropol. Peruana. № 1, pp. 3-48, Lima.

CARRIÓN, R.

1948 "La Cultura Chavín". Revista del Museo Nacional de Antropología y Arqueología. Vol II, № 1, Lima.

TABÍO, E.

1957 "Excavaciones en Playa Grande. Costa Central del Perú, 1955". Publicaciones del Instituto de Investigaciones Antropológicas. Vol. I, № 1, Lima.

UHLE, M

1912 "Die Muschelhügel von Ancon, Peru". XVIII Congreso Internacional de Americanistas, pp. 22-55, Londres.

WILLEY, G.R. y J.M. CORBETT

1954 "Early Ancon and Early Supe Culture". Columbia Studios in Archaeology and Ethnology. Vol III, New York.

Lima, enero 5, 1958. 